\title{
Guitarist Pick for Melena: A Unique Case of an Upper GI Bleed
}

\author{
Tiffany Lambrou, Vikas Khullar, Devi Rampertab, Roniel Cabrera \\ Division of Gastroenterology, Hepatology \& Nutrition, Department of Internal Medicine, University of Florida, Gainesville, \\ Florida, USA \\ Email: tiffany.lambrou@medicine.ufl.edu
}

How to cite this paper: Lambrou, T., Khullar, V., Rampertab, D. and Cabrera, R. (2017) Guitarist Pick for Melena: A Unique Case of an Upper GI Bleed. International Journal of Clinical Medicine, 8, 514-518. https://doi.org/10.4236/ijcm.2017.88048

Received: July 9, 2017

Accepted: August 28, 2017

Published: August 31, 2017

Copyright (c) 2017 by authors and Scientific Research Publishing Inc. This work is licensed under the Creative Commons Attribution International License (CC BY 4.0).

http://creativecommons.org/licenses/by/4.0/

\begin{abstract}
Gastrointestinal bleeds are a commonly observed complication after left ventricular assist device placement and usually caused by formation of arteriovenous malformations or acquired von Willebrand disease in the setting of anticoagulation use. We present a unique case of an upper GI bleed in which the cause was likely due to the impaction of a guitar pick into the duodenal bulb in the setting of continuous flow-LVAD on anticoagulation with elevated INR and discuss the pathophysiology of GI bleeds post-LVAD placement and relevant concerns about finding foreign bodies in the GI tract and their complications.
\end{abstract}

\section{Keywords}

Foreign Body, GI Bleed, Endoscopy, Left Ventricular Assist Device (LVAD)

\section{Introduction}

Gastrointestinal bleeds are a commonly observed complication after left ventricular assist device placement [1]. Most of these bleeds are due to formation of arteriovenous malformations or acquired von Willebrand disease in the setting of anticoagulation use [2] [3]. We present a unique case of an upper GI bleed in which the cause was likely due to the impaction of a guitar pick (plectrum) into the duodenal bulb in the setting of continuous flow-LVAD on anticoagulation with elevated INR and presented with melena and symptoms of acute blood loss anemia.

\section{Case Report}

A 70-year-old male with past medical history of end stage ischemic cardiomyo- 
pathy with left ventricular assist device (LVAD, HeartMate II, Pleasonton, CA) on warfarin, coronary artery disease status post five vessel CABG and implantable cardioverter-defibrillator, hypertension, hyperlipidemia and blindness presented to the emergency department with melena of one day duration with associated fatigue and lightheadedness.

On physical exam, vital signs showed temperature 98.0 F (normal range 97.8 F to $99.1 \mathrm{~F}$ ), pulse $101 \mathrm{bpm}$ (normal range 60 to 100 beats per minute), respiratory rate of 18 (normal range 12 to 18 breaths per minute), blood pressure 97/78 (normal range $90 / 60 \mathrm{~mm} / \mathrm{Hg}$ to $120 / 80 \mathrm{~mm} / \mathrm{Hg}$ ). His physical exam was normal, but rectal exam showed dark stool consistent with melena. He had a hemoglobin of $5.6 \mathrm{~g} / \mathrm{dL}$, down from his baseline hemoglobin between $11-12 \mathrm{~g} / \mathrm{dL}$, which was last checked three days prior. His platelets were within normal limits at 317 . BUN was elevated at 52 and creatinine was normal at 1.02. Given goal INR 2.5 to 3.0 for anticoagulation on LVAD, the patient's INR was elevated at 3.9. Sodium was decreased at $124 \mathrm{mEq} / \mathrm{L}$, otherwise electrolytes and liver function tests were normal. The patient was admitted to the cardiac intensive care unit for melena and acute blood loss anemia and started on proton pump inhibitor (PPI) infusion for upper gastrointestinal bleeding. Three units of packed red blood cells were given and gastroenterology was consulted. GI recommended proceeding with upper endoscopy (EGD), but was not able to perform the procedure initially due to the patient's elevated INR. Meanwhile, two more units of packed red blood cells were transfused with improvement of hemoglobin from 5.6 to 8.8.

Two days after admission, upper endoscopy was performed given INR 2.0. On EGD, diffuse mild inflammation characterized by linear erosions was found at the pylorus and a foreign body with small amount of oozing was seen in the duodenal bulb (Figure 1(a) and Figure 1(b)). The heart failure attending was called and he confirmed that the object seen in the duodenum is not a part of the LVAD. The patient's wife confirmed that the patient is an avid guitar player and may have used a guitar pick made by the company "Fender". Removal of the Fender guitar pick was then accomplished with a rat-toothed forceps and Roth net after several unsuccessful attempts. Post-retrieval, there were no ulcers or active bleeding seen in the duodenal bulb. Endoscopic images of retrieved foreign

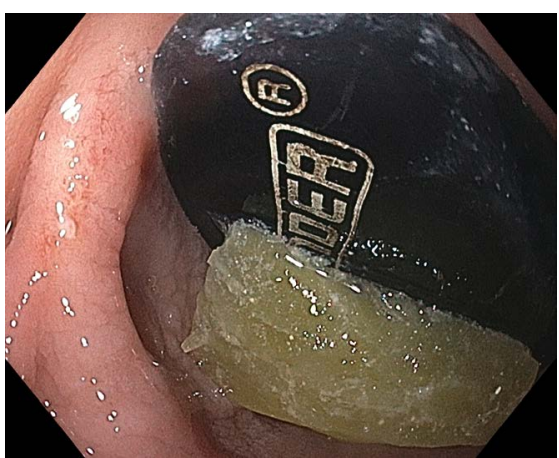

(a)

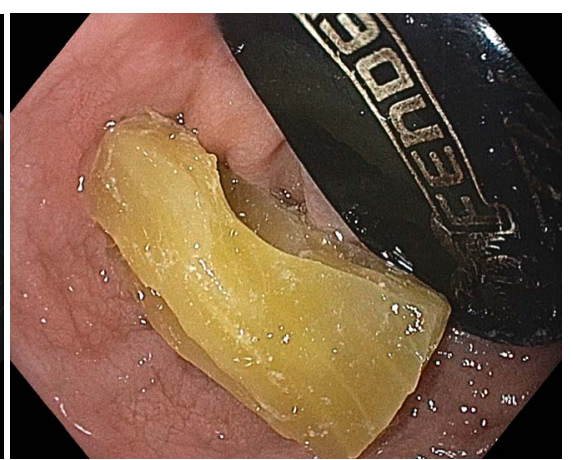

(b)

Figure 1. Endoscopic findings of a foreign body in the duodenal bulb. 


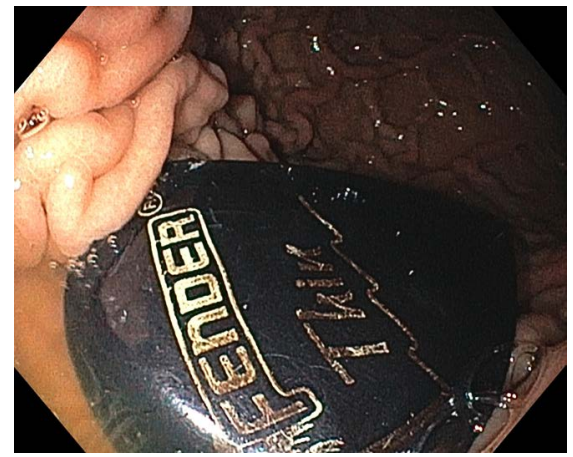

(a)

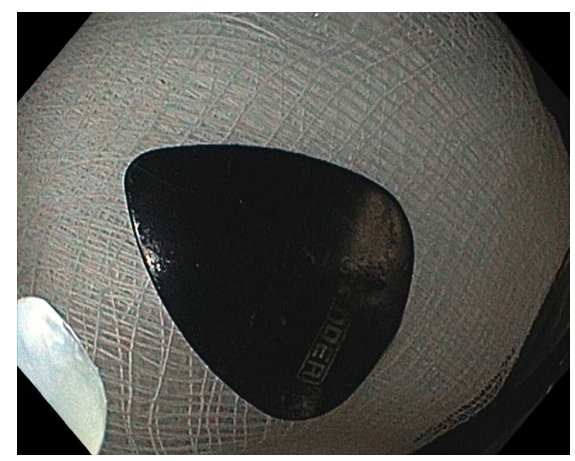

(b)

Figure 2. Endoscopic images of Fender guitar pick during (a) and post-retrieval (b).

body are shown in Figure 2(a) and Figure 2(b). The patient additionally underwent a small bowel enteroscopy several weeks later that showed no additional source of bleed.

\section{Discussion}

GI bleeds are a commonly observed complication after LVAD placement [1]. The incidence of GI bleed in patients with LVAD is estimated to be roughly $20 \%$, and most of these patients have continuous flow (CF) LVAD [4]. Most of the GI bleeds in these patients occur due to the formation of AVMs [2], which is thought to be caused by intestinal hypoperfusion from reduced pulse pressure in CF-LVADs leading to regional hypoxia and vascular dilation [5], but also due to an acquired von Willebrand disease, characterized by decreased or absent levels of high molecular weight von Willebrand factor multimers [2]. The reduction in these factors is also thought to be secondary to the narrow pulse pressure in CF-LVADs, mimicking Heyde's Syndrome seen in aortic stenosis [3]. In addition, CF-LVAD use requires the use of anticoagulation because of the hypercoagulable state associated with the device. Unfortunately, the risk for both thrombotic and hemorrhagic complications are increased compared to those on anticoagulation without LVAD, likely due to the impaired platelet aggregation secondary to acquired von Willebrand disease [2].

Our patient's initial presentation of melena and anemia suggested bleeding in the upper gastrointestinal tract, but this case is novel for the etiology of the bleed [6]. Finding a foreign body in the duodenum in a patient with LVAD raised concern for fistula formation or erosion of the hardware into the duodenum. Hence, the finding of such an object should raise concern for the endoscopist, and in our case, heart failure physicians were contacted for possible components of the LVAD into the duodenum. Fortunately, the word "Fender" was legible and thus helped with the conclusion that the foreign object is likely not a component of the LVAD. Given patient history of blindness and concern for foreign object, the patient's wife was contacted during the procedure prior to endoscopic retrieval. Foreign body ingestion is common, but the objects themselves typically pass without consequence and are thus rarely the cause of GI bleeding [7]. 
However, it is observed that foreign body ingestion is increased in those with sensorial deficiency, like blindness in this patient [8]. In conclusion, a thorough patient history at admission is important, and if a foreign body is found in the GI tract, it requires further investigation prior to retrieval.

Unsurprisingly, impacted foreign bodies in the GI tract lead to a high risk for the development of major complications such as perforated esophagus and mediastinitis, deep neck abscesses and aortoesophageal fistulas (AEF) [9]. AEFs are associated with high morbidity and mortality, and more than 100 cases have been reported as being associated with foreign bodies [10]. Therefore, the finding of an unsuspected foreign body in a patient with implanted devices should raise alarms for a possible fistula or erosion of the device into the GI tract. Thus, it is important to discuss with the surgeon or device manufacturer regarding the possible parts prior to tugging or removal.

In summary, it is suspected that the bleeding was likely due to the impaction of the guitar pick into the duodenal bulb in the setting of continuous flow-LVAD on anticoagulation with elevated INR, which led to acute blood loss anemia and the patient's presenting symptoms. After retrieval of the guitar pick, the patient was restarted on anticoagulation and discharged from the hospital in stable condition.

\section{Disclosures}

Informed consent was obtained for this patient.

\section{References}

[1] Harvey, L., Holley, C. and John, R. (2014) Gastrointestinal Bleed after Left Ventricular Assist Device Implantation: Incidence, Management, and Prevention. Annals of Cardiothoracic Surgery, 3, 475-479.

[2] Shrode, C.W., Draper, K.V., Huang, R.J., Kennedy, J.L.W., Godsey, A.C., Morrison, C.C., Shami, V.M., Wang, A.Y., Kern, J.A., Bergin, J.D., Ailawadi, G., Banerjee, D., Gerson, L.B. and Sauer, B.G. (2014) Significantly Higher Rates of Gastrointestinal Bleeding and Thromboembolic Events with Left Ventricular Assist Devices. Clinical Gastroenterology and Hepatology, 12, 1461-1467. https://doi.org/10.1016/j.cgh.2014.01.027

[3] Klovaite, J., Gustafsson, F. and Mortensen, S.A. (2009) Severely Impaired von Willebrand Factor-Dependent Platelet Aggregation in Patients with a Continuous-Flow Left Ventricular Assist Device (HeartMate II). Journal of the American College of Cardiology, 53, 2162-2167. https://doi.org/10.1016/j.jacc.2009.02.048

[4] Islam, S., Cevik, C., Madonna, R., Frandah, W., Islam, E., Islam, S. and Nugent, K. (2013) Left Ventricular Assist Devices and Gastrointestinal Bleeding: A Narrative Review of Case Reports and Case Series. Clinical Cardiology, 36, 190-200. https://doi.org/10.1002/clc.22096

[5] Demirozu, Z.T., Radovacevic, R., Hochman, L.F., Gregoric, I.D., Letsou, G.V., Kar, B.K., Bogaev, R.C. and Frazier, O.H. (2011) Arteriovenous Malformation and Gastrointestinal Bleeding in Patients with the Heart Mate II Left Ventricular Assist Device. The Journal of Heart and Lung Transplantation, 30, 849-853.

[6] Draper, K.V., Huang, R.J. and Gerson, L.B. (2014) GI Bleeding in Patients with 
Continuous-Flow Left Ventricular Assist Devices: A Systematic Review and Meta-Analyses. Gastrointestinal Endoscopy, 80, 435-436.

https://doi.org/10.1016/j.gie.2014.03.040

[7] Huiping, Y., Jian, Z. and Shixi, L. (2008) Esophageal Foreign Body as a Cause of Upper Gastrointestinal Hemorrhage: Case Report and Review of the Literature. European Archives of Oto-Rhino-Laryngology, 265, 247-249. https://doi.org/10.1007/s00405-007-0419-5

[8] Kubota, Y., Tokiwa, K., Tanaka, S. and Iwai, N. (1995) Intestinal Obstruction in an Infant Due to Magnet Ingestion. European Journal of Pediatrics, 5, 119-121. https://doi.org/10.1055/s-2008-1066183

[9] Kwong Lam, H.C., Sang Woo, J.K. and van Hasselt, C.A. (2003) Esophageal Perforation and Neck Abscess from Ingested Foreign Bodies: Treatment and Outcomes. Ear, Nose, \& Throat Journal, 82, 786-794.

[10] Medina, H.M., Garcia, M.J., Velazquez, O. and Sandoval, N. (2004) A 73-Year-Old Man with Chest Pain 4 Days after a Fish Dinner. Chest, 126, 294-297.

https://doi.org/10.1378/chest.126.1.294

\section{Scientific Research Publishing}

Submit or recommend next manuscript to SCIRP and we will provide best service for you:

Accepting pre-submission inquiries through Email, Facebook, LinkedIn, Twitter, etc. A wide selection of journals (inclusive of 9 subjects, more than 200 journals)

Providing 24-hour high-quality service

User-friendly online submission system

Fair and swift peer-review system

Efficient typesetting and proofreading procedure

Display of the result of downloads and visits, as well as the number of cited articles

Maximum dissemination of your research work

Submit your manuscript at: http://papersubmission.scirp.org/

Or contact ijcm@scirp.org 